\title{
The efficiency of macroporous polystyrene ion-exchange resins in natural organic matter removal from surface water
}

\author{
Agnieszka Urbanowska ${ }^{1,{ }^{*}}$, and Małgorzata Kabsch-Korbutowicz ${ }^{1}$ \\ ${ }^{1}$ Wroclaw University of Science and Technology, Faculty of Environmental Engineering, Chair in \\ Water and Wastewater Treatment Technology, Wybrzeze Wyspianskiego 27, 50-370 Wroclaw, \\ Poland
}

\begin{abstract}
Natural water sources used for water treatment contains various organic and inorganic compounds. Surface waters are commonly contaminated with natural organic matter (NOM). NOM removal from water is important e.g. due to lowering the risk of disinfection by-product formation during chlorination. Ion exchange with the use of synthetic ion-exchange resins is an alternative process to typical NOM removal approach (e.g. coagulation, adsorption or oxidation) as most NOM compounds have anionic character. Moreover, neutral fraction could be removed from water due to its adsorption on resin surface. In this study, applicability of two macroporous, polystyrene ion exchange resins (BD400FD and A100) in NOM removal from water was assessed including comparison of treatment efficiency in various process set-ups and conditions. Moreover, resin regeneration effectivity was determined. Obtained results shown that examined resins could be applied in NOM removal and it should be noticed that column set-up yielded better results (contrary to batch set-up). Among the examined resins A100 one possessed better properties. It was determined that increase of solution $\mathrm{pH}$ resulted in a slight decrease in treatment efficiency while higher temperature improved it. It was also observed that regeneration efficiency was comparable in both tested methods but batch set-up required less reagents.
\end{abstract}

\section{Introduction}

Natural organic matter (NOM) is one of the main group of contaminants present in surface and ground water sources. NOM is defined as a complex mixture of relatively low molecular weight compounds (e.g. amino acids, proteins) with macromolecular humic substances (humic and fulvic acids, humins) originating from natural decomposition of vegetable and animal remains [1-4].

Organic compounds are responsible for water colour, taste, smell and, most importantly, act as disinfection by-product precursors. Moreover, during water treatment they increase coagulant and disinfectant demand as well as create complexes with various anthropogenic

* Corresponding author: agnieszka.urbanowska@pwr.edu.pl 
contaminants. Furthermore, organic contaminants block surface of ion-exchange resins, foul membranes and support microbial growth in water supply network [5]. For these reasons, NOM should be removed from water sources intended for drinking water production [6].

Ion exchange with the use of ion-exchange resins is one of the available methods to remove ionic NOM [7]. NOM properties analysis indicates possibility of two removal mechanisms using ion-exchange resins: ion exchange due to electrostatic interaction between resin ionic groups and functional groups of organic macromolecules or physical adsorption of resulting from van der Waals forces between hydrophobic organic macromolecule centres and polymer matrix [8]. NOM removal efficiency from water using ion-exchange process ranges from 30 to $90 \%$ and depends on physico-chemical water properties, resin properties and process set-up [9].

Polystyrene macroporous ion exchange resins are one of the most commonly used in water treatment. Thanks to their structure allowing easy organic anion penetration, they are very useful in organic matter removal from water [10]. Water retention is an important property due to the fact that high moisture anion exchange resins have less compact structure thus allowing "slower" large particles (e.g. organic acids) binding $[11,12]$. Water content to ion-exchange capacity ratio strongly affects resin regeneration effectivity - from this point of view lower capacity is better because it leads to higher ratio value and thus easier regeneration.

In this study, two polystyrene macroporous ion exchange resins (BD400FD and Purolite A100) were used to remove organic matter from water and to compare removal process efficiency in various conditions and feed water properties. Moreover, the resin regeneration methods were examined.

\section{Materials and methods}

Properties of anion exchange resins used in these study can be found in Table 1.

Table 1. Ion-exchange resins characteristics $[13,14]$.

\begin{tabular}{|c|c|c|c|c|c|c|}
\hline Resin & Type & $\begin{array}{l}\text { Polymer } \\
\text { structure }\end{array}$ & $\begin{array}{l}\text { Particle size, } \\
\text { mm }\end{array}$ & $\begin{array}{c}\text { Functional } \\
\text { group }\end{array}$ & $\begin{array}{c}\text { Total } \\
\text { capacity, } \\
\text { eq } / \mathbf{d m}^{3}\end{array}$ & $\begin{array}{c}\text { Specific } \\
\text { gravity, } \\
\mathbf{k g} / \mathbf{m}^{3}\end{array}$ \\
\hline A100 & $\begin{array}{l}\text { weak } \\
\text { base }\end{array}$ & \multirow{2}{*}{$\begin{array}{c}\text { macroporous } \\
\text { polystyrene } \\
\text { crosslinked } \\
\text { with } \\
\text { divinylbenzene }\end{array}$} & $0.6-0.85$ (mean) & $\mathrm{R}-\mathrm{N}\left(\mathrm{CH}_{3}\right)_{2}$ & 1.13 & 1.04 \\
\hline BF400FD & $\begin{array}{c}\text { strong } \\
\text { base }\end{array}$ & & $\begin{array}{c}0.4-0.9(\geq 95 \%) \\
0.59-0.69 \\
\text { (mean) }\end{array}$ & $\mathrm{R}-\mathrm{N}^{+}\left(\mathrm{CH}_{3}\right)_{3}$ & $\geq 1.1$ & $1.05-1.09$ \\
\hline
\end{tabular}

Two model solutions of different origin but similar properties were subject of this study. Model solution 1 was taken from humic acid rich stream flowing from a peat-bog in the Table Mountains (Poland, sampling point location: 50²7’29.97' N; 16²3'16.87' E) while model solution 2 was prepared by mixing humic acids (Aldrich) with dechlorinated tap water $\left(0.02 \mathrm{~g} / \mathrm{dm}^{3}\right.$ solution).

Organic matter content in examined solutions was determined by colour intensity (absorbance of $350 \mathrm{~nm}$ wavelength), UV $254 \mathrm{~nm}$ absorbance as well as total (TOC) and dissolved organic carbon (DOC) measurements. TOC (DOC) concentration is the most reliable method for determining the total amount of NOM, UV adsorption at $254 \mathrm{~nm}$ monitors the amount of NOM fractions containing aromatic structures in their molecules, while the colour of water is related to the presence of large fractions of NOM. Model solutions properties can be found in Table 2 . 
Table 2. The properties of model solutions.

\begin{tabular}{|c|c|c|c|c|c|}
\hline \multirow{2}{*}{ Solution } & Colour & $\begin{array}{c}\text { UV 254 nm } \\
\text { absorbance }\end{array}$ & DOC & Conductivity & pH \\
\cline { 2 - 6 } & $\mathrm{g} \mathrm{Pt} \cdot \mathrm{m}^{-3}$ & $\mathrm{~cm}^{-1}$ & $\mathrm{~g} \mathrm{C} \cdot \mathrm{m}^{-3}$ & $\mu \mathrm{S} \cdot \mathrm{cm}^{-1}$ & - \\
\hline Model solution 1 & 99.54 & 0.693 & 11.98 & 337 & 4.84 \\
\hline Model solution 2 & 104.58 & 0.526 & 11.86 & 679 & 7.25 \\
\hline
\end{tabular}

Anion exchange resin preparation for the use in the ion exchange process included converting it into chloride form by soaking it in $12 \% \mathrm{NaCl}$ solution and then washing it out using distilled water.

Water treatment in batch ion exchange set-up was conducted in $2 \mathrm{dm}^{3}$ jar containing $1 \mathrm{dm}^{3}$ of examined solution and given resin dose $\left(1,2.5,5,10,20,30\right.$ or $\left.40 \mathrm{~cm}^{3}\right)$. Jar content was mixed using magnetic stirrer $(135 \mathrm{rpm})$ to assure equal resin bead distribution and keeping it in suspended state. Stirring for 5 to 60 minutes was followed by $30 \mathrm{~min}$ sedimentation. The temperature of solutions amounted to $20^{\circ} \mathrm{C}$.

Ion exchange in flow set-up was performed in a $20 \mathrm{~cm}$ glass column, $13 \mathrm{~mm}$ of internal diameter, containing $15 \mathrm{~cm}^{3}$ of resin. Examined solution flux velocity through resin bed was $15 \mathrm{~cm}^{3} \cdot \mathrm{min}^{-1}$. Process was carried on for 180 to $300 \mathrm{~min}$. $\mathrm{pH}$ and feed temperature influence on NOM removal efficiency was examined in $2-10$ and $20-40^{\circ} \mathrm{C}$ ranges respectively.

Resin regeneration in batch set-up was carried similarly to resin preparation: exhausted resin was soaked in $200 \mathrm{~cm}^{3}$ of $12 \% \mathrm{NaCl}$ solution and stirred using magnetic stirrer for 30 min with the intensity keeping resin in suspended state. Afterwards, spent regenerant was decanted and resin was washed using distilled water until no chloride ion could be detected. Resin regeneration in flow mode was preceded by its backwashing with distilled water in order to loosen resin beads and remove gas bubbles. Than regenerant was passed through the resin bed for $120 \mathrm{~min}$ with flow velocity $6 \mathrm{~cm}^{3} \cdot \mathrm{min}^{-1}$. Finally resin was washed-out with distilled water till no chlorides were detected in the effluent.

Regeneration efficiency was determined by comparing NOM removal for regenerated and fresh resin.

\section{Results}

Experiments conducted in order to assess polystyrene ion exchange resins usefulness in NOM removal from water allowed determination of resin dose, its type, contact time and process set-up influence on water treatment efficiency. Results presented in Figure 1 obtained for batch set-up shows that NOM removal efficiency from water improves together with prolonged contact time of resin with contaminants and with increasing resin dose. It was observed that ion exchange intensity (amount of NOM removed in an unit of time) was highest at the beginning of a process with further gradual slowdown. It was observed that optimal stirring time was 40-60 min. Prolonged stirring only slightly improved NOM removal efficiency after $60 \mathrm{~min}$. Kinetic curves show (Figure 1) that UV $254 \mathrm{~nm}$ absorbance decreased with increasing resin dose (analogous results for colour intensity and DOC removal were recorded). Together with increased resin amount, more organic anions might be exchanged for chloride ions on resin active sites. Lower resin dose provides less active sites on resin beads of which only part is available for weak organic ions. For example, after stirring model solution 1 for 30 min with A100 resin dosed at $5 \mathrm{~cm}^{3} / \mathrm{dm}^{3}$ UV $254 \mathrm{~nm}$ absorbance decreased to $0.595 \mathrm{~cm}^{-1}$ while twice higher resin dose $\left(10 \mathrm{~cm}^{3} / \mathrm{dm}^{3}\right)$ resulted in absorbance removal to $0.482 \mathrm{~cm}^{-1}$. 

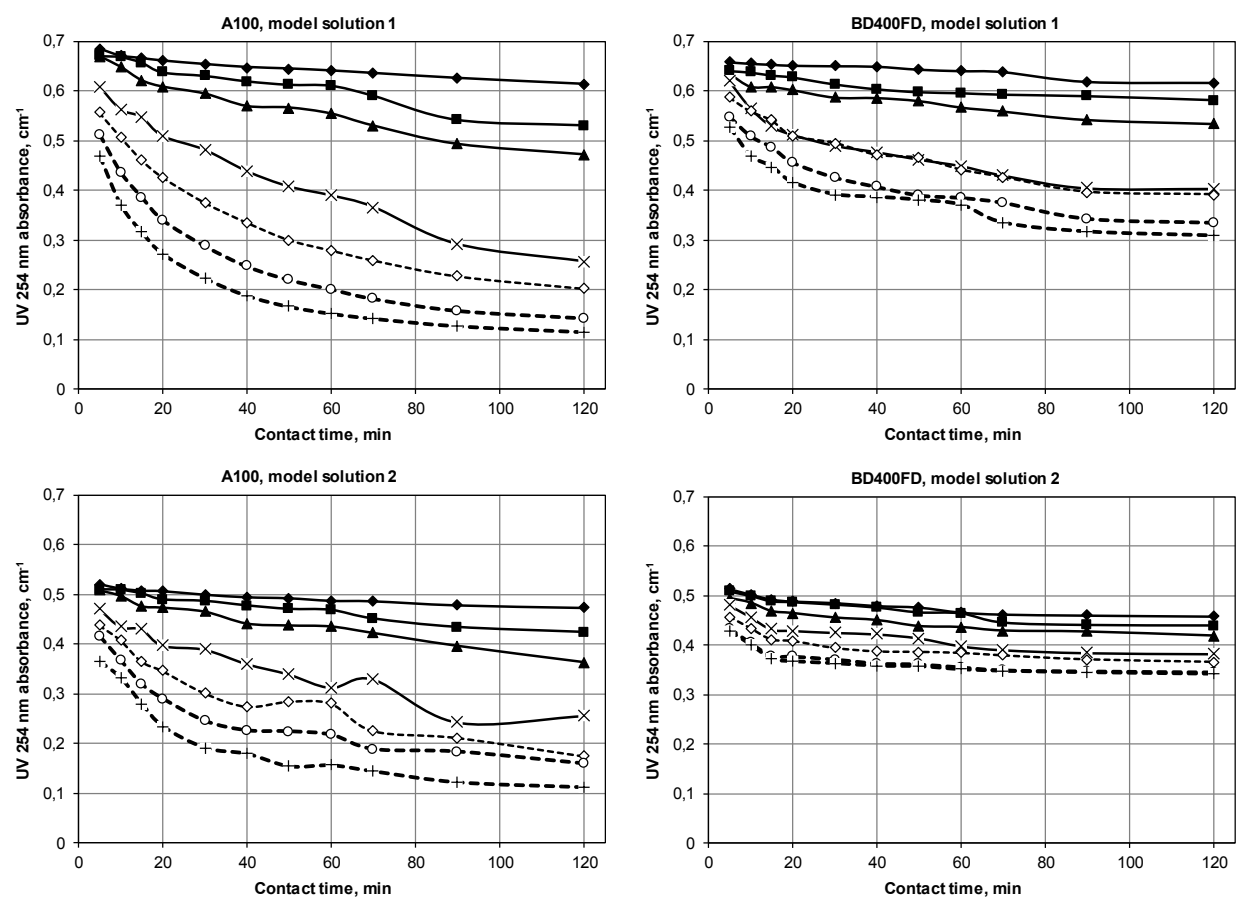

$\longrightarrow-1 \mathrm{~cm}^{3} / \mathrm{dm}^{3} \longrightarrow-2,5 \mathrm{~cm}^{3} / \mathrm{dm}^{3} \longrightarrow-5 \mathrm{~cm}^{3} / \mathrm{dm}^{3} \longrightarrow \times-10 \mathrm{~cm}^{3} / \mathrm{dm}^{3}--\diamond--20 \mathrm{~cm}^{3} / \mathrm{dm}^{3}-\infty--30 \mathrm{~cm}^{3} / \mathrm{dm}^{3}--+-40 \mathrm{~cm}^{3} / \mathrm{dm}^{3}$

Fig. 1. NOM removal in batch set-up (UV $254 \mathrm{~nm}$ absorbance vs contact time).
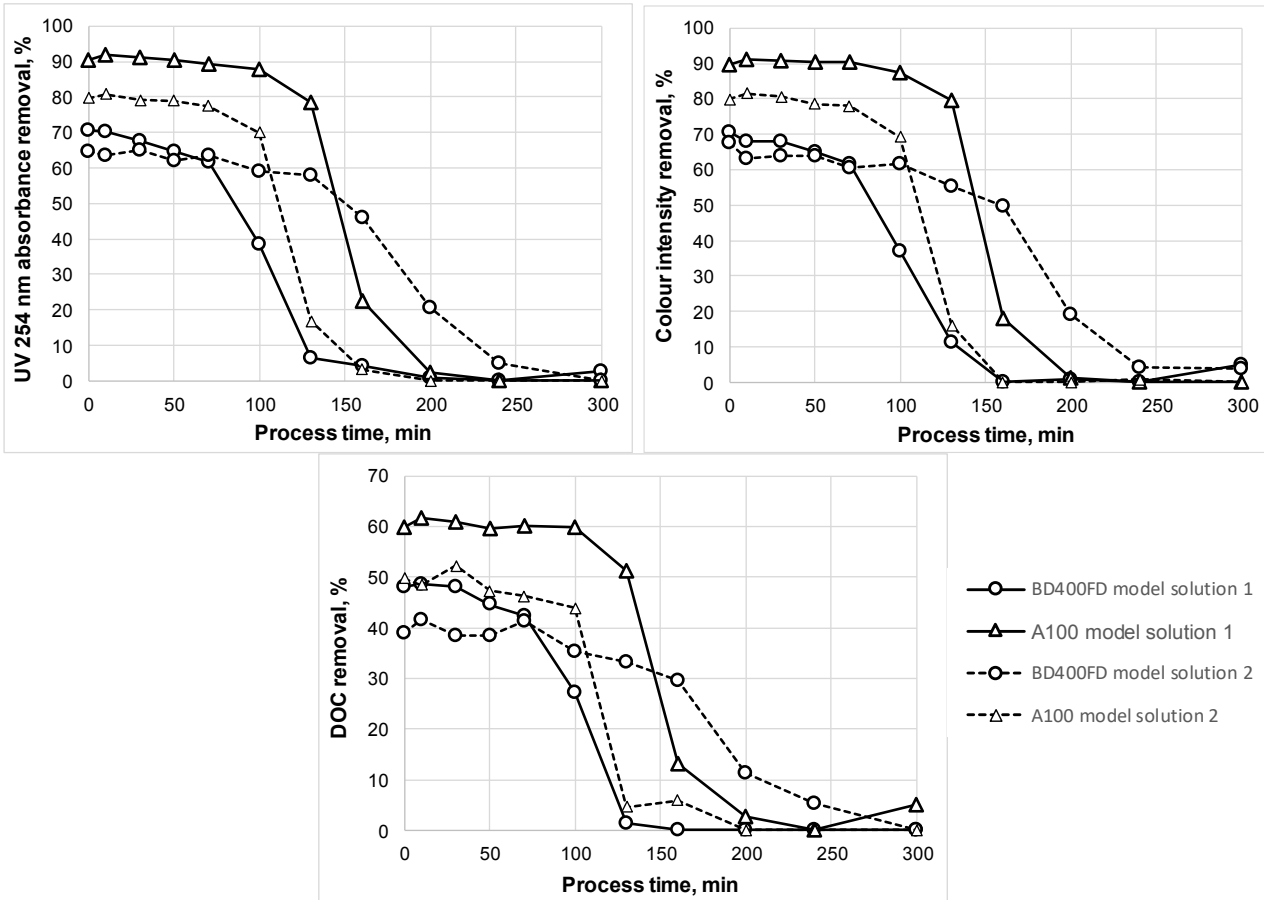

- B BD400FD model solution 1

$\triangle$ A100 model solution 1

--O- BD400FD model solution 2

-- $\Delta-$ - A100 model solution 2

Fig. 2. NOM removal in flow set-up. 
Results obtained for flow set-up experiments are shown in Figure 2 and are consistent in terms of nearly constant, low, colour intensity, UV $254 \mathrm{~nm}$ absorbance and DOC concentration levels in the first minutes of running process followed by increasing levels up to values equal to those measured for raw solutions. It is important to observe that none of the resins removed NOM in 100\%. Moreover, NOM fractions responsible for UV $254 \mathrm{~nm}$ absorbance and colour were retained to the same extent, but DOC reduction was noticeably lower. For example for model solution 2, in the first 50 minutes of process organic substances responsible for colour intensity were removed in $79 \%$ and $64 \%$ of, ones measured as UV $254 \mathrm{~nm}$ absorbance in $79 \%$ and $62 \%$ of, while DOC was eliminated only in $47 \%$ and $38 \%$ with the use of the A100 and BD400FD resins, respectively.

Comparing the effects obtained in both investigated process set-ups it was observed that flow set-up performed better in terms of water treatment efficiency. It was due to the fact that in the batch mode feed water and resin mixing occurred until reaching equilibrium followed by decantation. Equilibrium state, in which NOM concentration is lower than in initial solution, limited resin ion exchange capacity utilization. In the flow set-up on the other hand at any time "fresh" feed solution contacted resin bed which allowed much better resin capacity utilization.

Resin type was another NOM removal decisive factor. Obtained results shown that A100 was the most effective resin which allowed to remove DOC, colour intensity and UV $254 \mathrm{~nm}$ removal up to $62 \%, 92 \%$ and $91 \%$ respectively in flow set-up while BDF400FD reached only $49 \%, 71 \%$ and $71 \%$. Both examined resins are macroporous which facilitates penetration by micropollutants and retaining them inside resin structure. In such a situation sorption is decisive when it comes to NOM removal efficiency. Tested resins differ by basicity: A100 is weak base while BD400FD is strong base one. Obtained results are contrary to the literature by which weak base anion exchange resins should perform noticeably worse than strong base when it comes to NOM removal [15]. It was probably caused by BD400FD ion exchange capacity being lower than declared in product sheet.

NOM removal efficiency was also affected by composition of treated water. Obtained results shown that for both resins better treatment effect was achieved for model solution 1 . Aldrich NOM (solution 2) which has larger NOM molecules [16], were removed in lower extent as compared to low molecular weight organic compounds typical for natural waters (solution 1). Moreover higher concentration of inorganic anions in solution 2 deteriorated organic anions uptake by resins.

Experiments on solution $\mathrm{pH}$ influence on NOM removal efficiency (Figure 3.) demonstrated that the increase of $\mathrm{pH}$ up to 10 deteriorated organic macro-anion removal. For example, treating model solution 1 in flow set-up with the use of BD400FD resin at $\mathrm{pH}$ 10 after 30 minutes of process resulted in $46 \%$ of colour intensity, $43 \%$ of UV $254 \mathrm{~nm}$ absorbance and $29 \%$ of DOC decrease, respectively, which is significantly less than for original solution ( $\mathrm{pH} 4.84: 68 \% 67 \%, 48 \%$ ). It can be assumed that alkalinisation of the feed solution increased concentration of inorganic anions competing with organic ions for resin active sites and furthermore progressing organic compound functional groups dissociation increased particles sizes thus impeding ion exchange. 

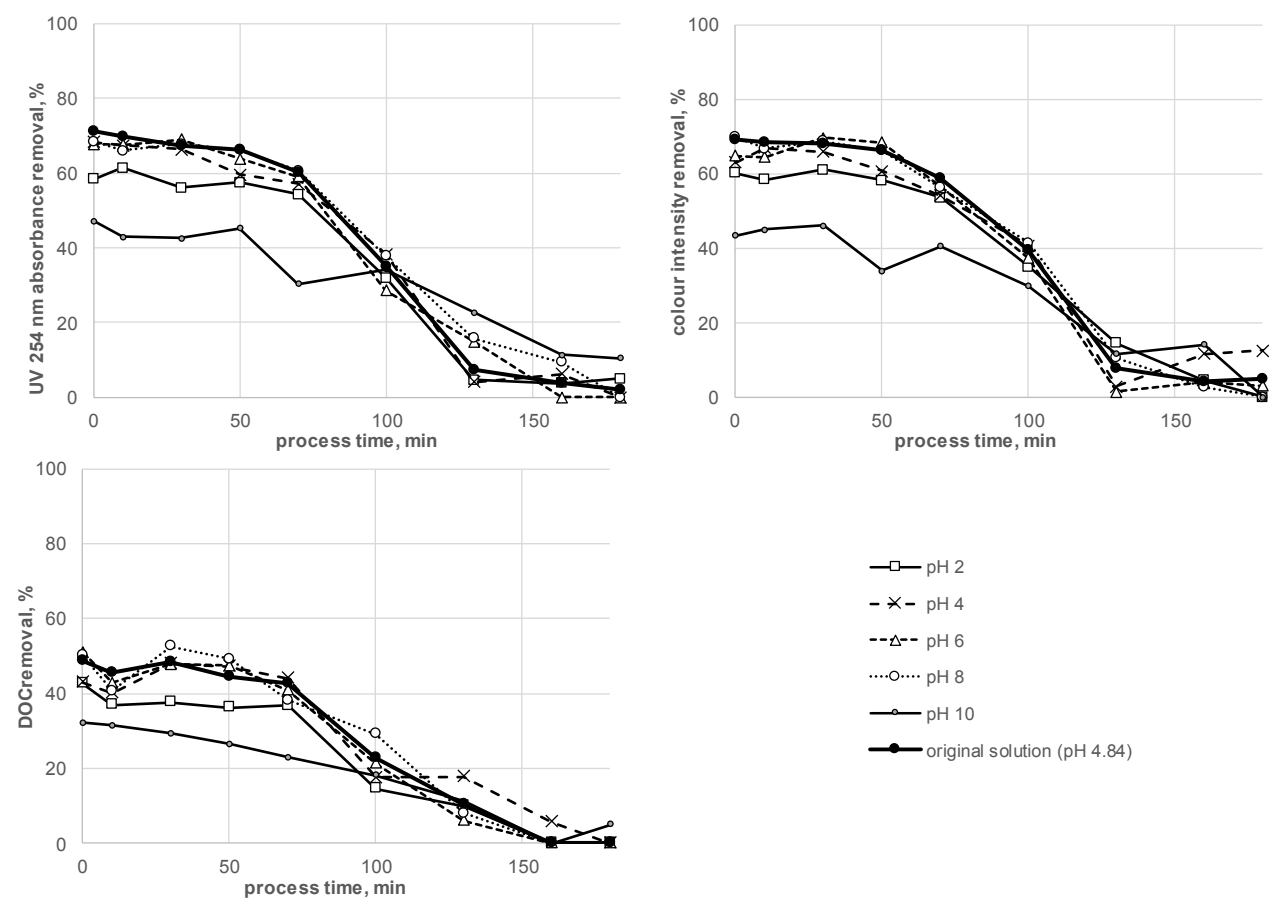

Fig. 3. Solution $\mathrm{pH}$ influence on NOM removal from model solution 1 by BD400FD resin in flow set-up.
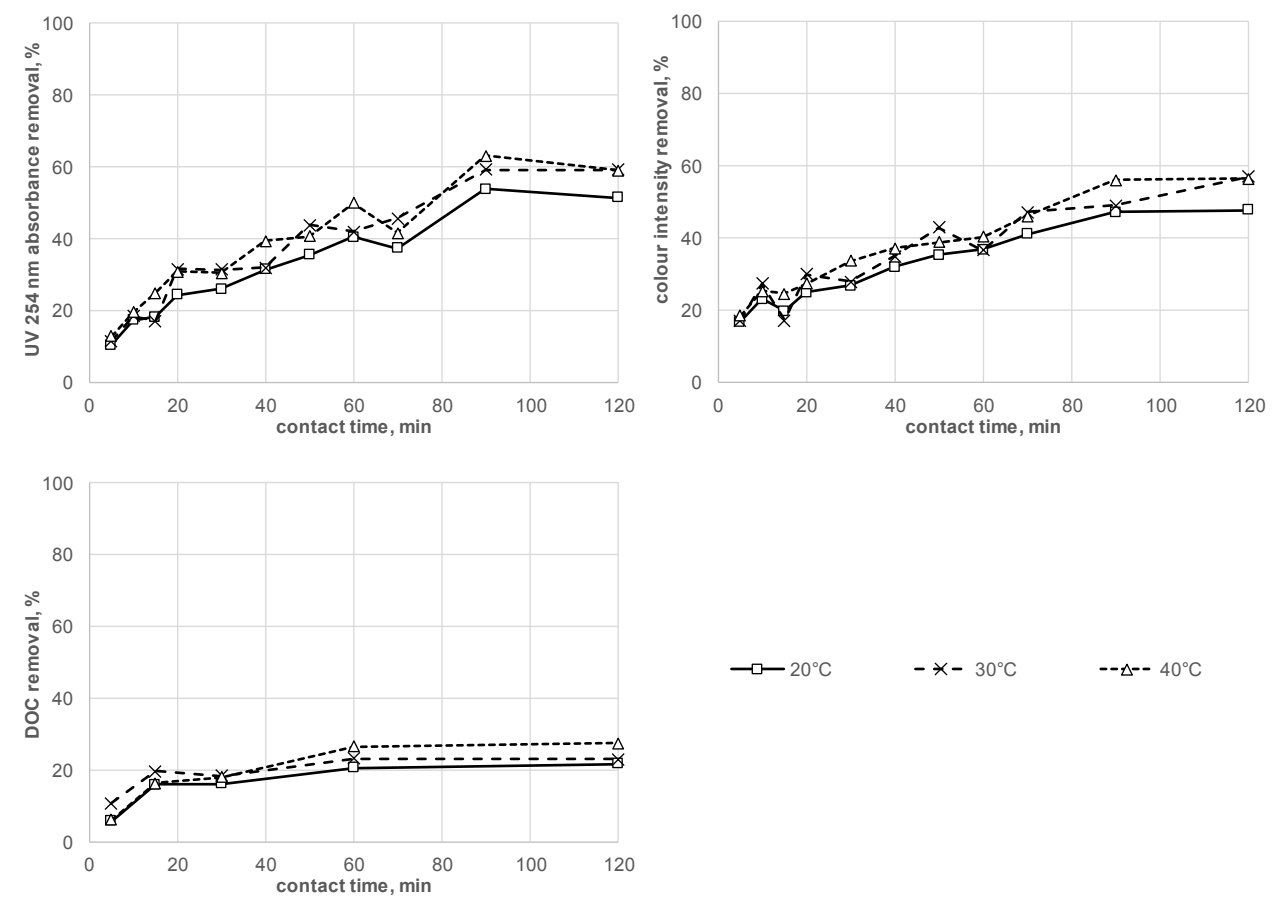

Fig. 4. Temperature influence on NOM removal from model solution 2 by A100 resin in flow set-up. 
Results presented in Figure 4. shows that feed solution temperature also influenced ion exchange performance. The increase of temperature from $20^{\circ} \mathrm{C}$ to $40^{\circ} \mathrm{C}$ improved ion exchange efficiency which might be due to the fact that higher temperature accelerated exchanging ions movement, loosened resin structure (thus facilitated large ions diffusion into resin), increased functional groups dissociation and decreased pressure loss in resin bed.
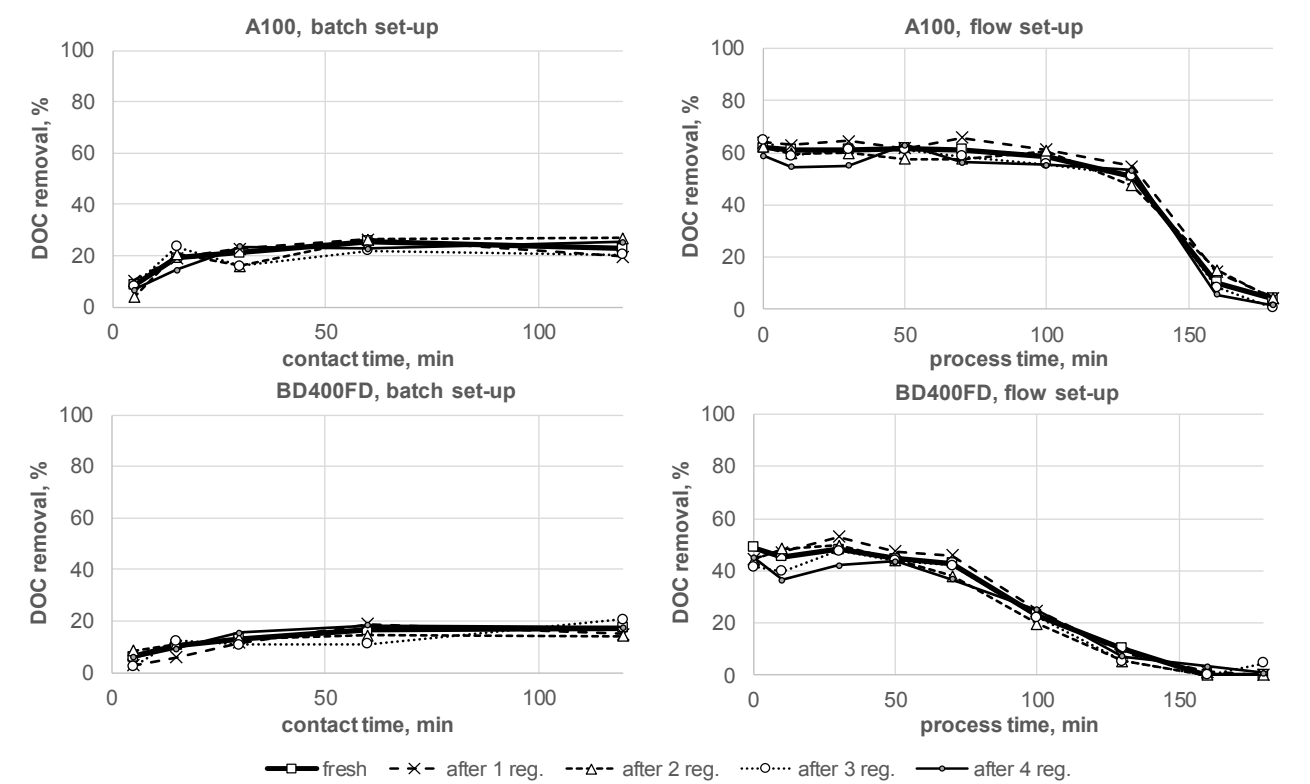

Fig. 5. DOC removal from model solution 1 by fresh and regenerated resins (set-up type indicates both regeneration and NOM removal efficiency tests).

Ion exchange resin regeneration experiments focused on restoring sorption capacity enabled comparison of two regeneration methods. It can be seen (Figure 5) that both flow and batch set-ups gave similar results (no significant difference in fresh and regenerated resin DOC removal efficiency), however the latter one required more regenerating agent, thus making it much less economically effective. In the case of batch tests, desorbed contaminants kept circulating in jar, competing with regenerating agent inorganic ions for resin active sites. On the contrary, in flow set-up desorbed NOM was immediately removed from bed while resin beds constantly contacted fresh regenerating agent.

\section{Conclusions}

Conducted experiments showed that ion exchange process with the use of synthetic polystyrene resins can be effectively used in NOM removal from water. Resin type and its dosed amount as well as contact time were found to be one of the decisive factors of process effectiveness. Longer contact time and higher resin dose resulted in better treated water quality. A100 was found to be more efficient. Comparison of process set-up influence on NOM removal proven flow set-up to be noticeably more effective. It was shown that physico-chemical properties of treated water were not without significance: the increase of solution $\mathrm{pH}$ slightly worsened process performance while the temperature rise improved water treatment efficiency. Moreover, resin regeneration studies revealed that both examined set-ups allowed for similar effect, but with different regenerating agent consumption. 


\section{References}

1. A.M. Sillanpää, Natural Organic Matter in Water: Characterization and Treatment Methods (Butterworth-Heinemann, London, 2014)

2. A. Matilainen, M. Vepsäläinen, M. Sillanpää, Adv. Colloid Interface Sci. 159 (2010)

3. A. Matilainen, E.T. Gjessing, T. Lahtinen, L. Hed, A. Bhatnagar, M. Sillanpää, Chemosphere, 83 (2011)

4. J.A. Leenheer, J.-P. Croue, Environ. Sci. Technol. 37 (2003)

5. A. Grefte, M. Dignum, E.R. Cornelissen, L.C. Rietveld, Drink. Water Eng. Sci. 6 (2013)

6. J.-Q. Jiang, H.-Y. Wang, Sep. Sci. Technol. 44 (2009)

7. J.P. Croue, G.V. Korshin, M.M. Benjamin, Characterization of Natural Organic Matter in Drinking Water (American Water Works Association, 2000)

8. P.S. Bäuerlein, T.L. ter Laak, R.C.H.M. Hofman-Caris, P. de Voogt, S.T.J. Droge, Wat. Res. 46 (2012)

9. N. Ates, F.B. Incetan, Ind. Eng. Chem. Res. 52 (2013)

10. T.H. Boyer, P.C. Singer, Environ. Sci. Technol. 42 (2008)

11. B. Bolto, D. Dixon, R. Eldridge, React. Funct. Polym. 60 (2004)

12. A.A. Zagorodni, Ion Exchange Materials: Properties and Applications (Elsevier, 2007)

13. Purolite ${ }^{\circledR}$ A100 Product Data Sheet, http://www.lenntech.com/Data-sheets/PuroliteA100-L.pdf

14. BD400FD Anion exchange resin data sheet

15. E.R. Cornelissen, N. Moreau, W.G. Siegers, A.J. Abrahamse, L.C. Rietveld, A. Grefte, M. Dignum, G. Amy, L.P. Wessels, Wat. Res. 42 (2008)

16. S.A. Parsons, B. Jefferson, P. Jarvis, E. Sharp, D. Dixon, B. Bolto, P. Scales, Treatment of Waters with Elevated Organic Content (AWWA Pub., 2007) 